\title{
Assessment of Peer Mentoring of Teams in a First-Year Design-Build-Test- Communicate Class
}

\section{Mr. James A. Coller, University of Michigan}

James Coller is an engineering graduate student at the University of Michigan where he also completed his B.S. in Naval Architecture and Marine Engineering in 2017. He spent three years during his undergraduate education as an Instructional Assistant for a first year engineering course. His research interests include autonomous robotics for both land and marine environments as well as naval ship design problems.

\section{Mr. Magel Su, University of Michigan}

Magel Su is a current undergraduate student at the University of Michigan studying materials science and engineering with a minor in chemistry. He is also a member of the engineering honors program, an instructor for a first-year engineering design course, and a researcher in the Yalisove Lab Group.

\section{Dr. Laura K. Alford, University of Michigan}

Laura K. Alford is a Lecturer and Research Investigator at the University of Michigan.

\section{Dr. Stephanie Sheffield, University of Michigan}

Dr. Sheffield is a Lecturer in Technical Communication in the College of Engineering at the University of Michigan.

\section{Dr. Robin Fowler, University of Michigan}

Robin Fowler is a lecturer in the Program in Technical Communication (College of Engineering, University of Michigan). She particularly enjoys coaching students through the difficult rhetorical situations of open-ended design projects. 


\title{
Assessment of Peer Mentoring of Teams in a First Year Design-Build-Test- Communicate Class
}

\begin{abstract}
Peer mentoring has been associated with beneficial outcomes in higher education, from increased retention of minority students ${ }^{[1]}$ and women ${ }^{[2]}$ to learning gains for both mentors and mentees ${ }^{[3]}$. Most of the peer mentoring relationships investigated in the literature are of mentors not tied to a specific course [e.g., ${ }^{2}$ ]. This paper reports on how one section of a first year, intensive, projectbased learning class uses peer mentors to guide student teams throughout a design-build-test project in a first year engineering course.
\end{abstract}

Our one-semester course is a four-credit combined technical and communication course. Students work in teams of four or five students to design, build, and test two underwater vessels (one an unpowered bathysphere, one a remotely operated vehicle [ROV]), as well as to report on those designs. Former students of the course participate as peer mentors, working directly with a single team to guide design decisions and provide feedback on all facets of the design and communication process.

In Fall 2016, we conducted an assessment of our current peer mentoring system by surveying students and peer mentors. As all students in our section experience mentoring, we did not have a comparison group, but we did seek to understand the benefits and drawbacks of mentoring for both students and mentors. From this survey, as well as our experiences facilitating the course with peer mentors for eight semesters, we are able to report a few "best practices" for facilitating the peer mentoring experience in our context. Importantly, we find that both students and mentors benefit from the mentoring experience, enough to justify our efforts to manage it. We do note potential disadvantages of mentors, as well as possible ways to mediate these drawbacks. This report contains the results of the survey, as well as instructor conclusions on what aspects of the peer mentoring experience are most important for successful implementation.

\section{Introduction}

Peer mentoring has been associated with beneficial outcomes in higher education, from increased retention of minority students ${ }^{[1]}$ and women ${ }^{[2]}$ to learning gains for both the mentors and mentees ${ }^{[3,4]}$. Mentors are also found to develop in pedagogical/life skills including patience, confidence, communication, and leadership ${ }^{[4,5]}$.Most of the peer mentoring relationships investigated in the literature are mentors not tied to a specific course [e.g., ${ }^{2}$ ]. In the literature, this type of role is sometimes called "peer leader" or "peer facilitator," and the students who fulfill the role are sometimes true peers and sometimes older and more experienced than the students they mentor. Mentors are sometimes paid or rewarded with course credit.

This paper reports on how one section of a first year, intensive, project-based learning class uses peer mentors to guide student teams throughout a design-build-test project in a first year engineering course. The authors of this paper are closely tied to the course. Much of the assessment work was done by two undergraduate instructional assistants for the course, one of 
whom is also a former peer mentor. All other authors of the paper are faculty members who regularly serve as technical or communication instructors in the course, and who train and manage the mentors and student teams. This paper represents scholarship of application ${ }^{[6]}$, capturing the implementation of peer mentors in our course. As such, we have attempted to describe the relevance of our pedagogical efforts, our intended outcomes, and the context of the work in some detail.

Our data regarding outcomes of the experience for both mentors and mentees come from surveys conducted at the end of the semester, though we recognize that self-reported information from the end of the semester is not the perfect tool ${ }^{[7]}$. In the future, we may collect information throughout the semester to see how students' and mentors' perspectives change over time.

This study follows a scholarship of teaching and learning (SoTL) process. We seek to evaluate something we are doing in the classroom; we did not begin with a theoretical framework like engineering self-efficacy or teaching self-efficacy, though we believe both are relevant to this study.

\section{How we use peer mentors in our first year engineering course}

Our first year course is a four-credit introductory engineering course all incoming first year engineering students take at our institution. Students select into one of about a dozen different sections, each with a different project/theme (see [8] for a more thorough description of the general course and the underlying pedagogy). The course covers technical content specific to a topic (e.g., digital signal processing, wind power), as well as "professional skills" such as communication, teamwork, and ethics.

This research project was conducted only with students who selected into our specific section. As other engineering 100 courses have different instructors, different projects, different team sizes, and different project deliverables, other sections were not considered a viable comparison group, even though many of them do not use peer mentors for the course projects.

In our section, which was first developed in 2012 and has used peer mentors every semester, students work on teams of 4-5 students to design, build, test, and communicate about an unpowered bathysphere ( 2 week project) and a remotely operated vehicle (ROV; $\sim 7$ week project). The teams are shuffled between projects: students work with one group of students on the bathysphere and a new group of students for the ROV.

Students in the course have 6 weekly contact hours: two 1.5-hour lectures, one 1-hour discussion section, and one 2-hour lab. The discussion section and lab are contiguous to allow for flexibility some weeks. There are 60 students in the overall course, and they are all in the same lecture; they are split between three discussion/lab sections of 20 students each.

The course has a large instructional team. Two full-time faculty members, one from the Naval Architecture and Marine Engineering Department and one from the Program in Technical Communication, share the course organization and the lectures. That communication instructor plus another full-time faculty member from the Program in Technical Communication share the discussion sections. The labs are run by an Instructional Assistant (a paid undergraduate position; 
three instructional assistants run the three labs, with one primarily responsible for each one) and a lab manager (a full time staff member who coordinates the lab space and materials).

Mentors are recruited from previous semesters of the course. At the end of each semester, alumni of the course receive an email inviting them to apply to serve as a peer mentor. They can do so for one pass/fail credit, or simply for the experience. Most choose to earn the credit (because of the tuition policies at our institution, most students do not pay extra for this credit). While there is no official policy regarding a student's performance in the class and requirements to become a mentor, we are generally able to select strong performers to offer the mentoring roles to. Because of the relatively small size and intensity of the class, we get to know most students well, and we generally have a good sense of a student's motivation, commitment, command of the technical and communication material, and potential for leadership when we decide which students to use as mentors.

Though our institution matches national numbers regarding enrollment of women $\left(\sim 30 \%{ }^{[8]}\right)$, our section enrolls slightly fewer women (22.5\% over the last four semesters). Interestingly, though women are underrepresented among our students, they are overrepresented among those students who indicate an interest to mentor and among those students who end up serving as peer mentors ( 21 of 36 mentors in Fall 2016 and Winter 2017 are women).

When mentors are selected, they are assigned at the lab level. Each 20-person lab has four teams and four mentors. Mentors who are selected for the lab have indicated their availability to attend one hour of the two-hour lab time in that space, and mentors are expected to attend project labs with their teams. Mentors are assigned to the teams in a pseudo-random fashion. As the instructors make the teams, we sometimes have a sense that a particular team may struggle in some way, and we might be able to mediate our concerns by selecting an appropriate mentor for the team. For example, we might have created a team with an isolated woman or minority student, and we can assign a mentor intentionally (e.g., assign a female mentor to a team of four men and one woman). One semester, a student's learning disability affected her focus on individual tasks early in the semester, and we worried that she would not complete tasks for her team. We selected a mentor who we knew was particularly understanding and conscientious, and we coached her on what this student might need. The mentor arranged for face-to-face work sessions (as we understand it, both the student and mentor focused primarily on their own tasks, but they sat next to each other in the library to do so, and the mentor reminded the student of strategies periodically). The student was much more successful after this mentor "took her under her wing," both on individual work and on her portions of the team project.

Our efforts to prepare mentors continue to evolve. In recent semesters, we have held an initial training session with the mentors in the evening before the projects start, and we talk with the mentors about what an excellent mentor should do. Much of the content at this meeting comes from the mentors themselves: they are all students of the course who experienced mentoring, and they are generally happy to talk about what their mentors did, and how it worked well (or did not work well) for their team. This semester, we have added two elements to our preparation of mentors: a reading on facilitating group conversations and on reactive teaching (modified from [9], originally for a graduate student instructor audience, by our Center for Research on Learning and Teaching), and a weekly email (from a former instructional assistant and experienced peer 
mentor) reminding mentors of what their teams should be doing this week and what goals the team needs to meet.

Mentors serve their teams in a variety of capacities, and one reason we conducted the survey reported in this paper is that we realized we don't know all of the ways they perform their mentoring roles. Another reason for the survey was to gain understanding from the mentors and students about the usefulness and importance of the various aspects of the peer mentor role. When mentors sign up to be mentors, they are committing to attend one hour of the lab session weekly, during the projects. They are also committing to provide "out-of-class support" and to helping run the bathysphere and ROV competitions.

Because we are in the lab and at the competitions, we have a better sense of what mentors do in those spaces. We have less of a sense of the variety of ways mentors help teams outside of class, or even of how common it is for mentors to make significant out-of-class efforts. We hear of mentors rehearsing presentations with teams, reading and responding to report drafts, helping teams to gauge task effort requirements for Gantt Charts, and showing teams collaboration tools. We are very interested to learn whether these are common ways that mentors help teams, and what efforts are perceived as most beneficial.

One strong benefit of having mentors is that they help the instructional team better understand student needs. Originally, we learned about student needs through an informal and natural process. The mentors generally know us well, after completing a whole semester with us, and they are more willing to come to us to explain issues students are having (with teams, with understanding of course expectations, etc.) Having a better sense of what students needed allowed us to be responsive to those needs. For the last three semesters, we have formalized this reporting. Mentors now fill out a short Google form after each meeting with the team, letting us know what their team worked on, whether the team is on track to finish the project as expected, and whether there are topics we should be addressing in class-- or team issues we should be addressing-- to help the students be more successful. This feedback is reviewed at our weekly staff meetings, allowing us to promptly intervene as necessary.

Though coordinating the mentor experience in this course has added an extra level of administration work, we believe it is worth it, both for the experience of the currently enrolled students, and for the mentors. To better understand student and mentor perspectives, we conducted surveys, reported below.

\section{Survey assessment of peer mentoring experience}

Methodology. To assess students' and peer mentors' experiences with peer mentoring throughout the course, we conducted two surveys, one for students and one for peer mentors, with questions designed to complement one another. The survey content was designed to assess the following topics: the effects of peer mentors on mentor and mentee development both as individuals and as part of a student team, the specific tasks that peer mentors helped students with, the amount of time that peer mentors and students spent together, and the perceptions that peer mentors had of their own actions. 
Participants. The student participants were recruited from 112 first-year students enrolled across our two sections of an introductory engineering design course in the fall semester of 2016. All of the students were also enrolled in one of six corresponding laboratory sections, with no more than 20 students in a laboratory section. Four laboratory sections had 20 students, one section had 19 students, and one section had 13 students. Of the 112 students, 27 (24\%) students participated in the survey.

The peer mentors who participated in the survey were recruited from 36 students who had previously taken the same introductory engineering design course and laboratory section and were peer mentors within the last two years. Specifically, students who had peer mentored during the following semesters were asked to participate in the survey: Winter 2014, Fall 2015, Winter 2015, Fall 2016. While there were 12 peer mentors every semester, excluding Fall 2016 which had 23 peer mentors, there was only a total of 36 peer mentors due to overlap between semesters. Of the 36 peer mentors, 16 (44\%) peer mentors participated in the survey.

The surveys were sent out to students and peer mentors at the end of the Fall 2016 semester by a course instructor. The peer mentor survey was sent out first to all 36 peer mentors as a link to a Qualtrics survey in an email immediately following the last day of class, but before final examinations began. One week later, the email was sent out again to solicit more responses. The corresponding student survey was sent out after final grades for the course were released to prevent students from feeling pressured to participate in the survey. The student survey was sent out as a link to a Qualtrics survey in a public announcement on the Fall 2016 course website, where it was viewable by all 112 students. One week later, another announcement was made to solicit more responses.

Design. Two surveys were designed, one for students and one for peer mentors. Both surveys were designed with three sections: rating statements on a Likert scale (Strongly Agree, Agree, Neutral, Disagree, Strongly Disagree), selecting all of the appropriate choices, and short responses, all of which combined could be completed in a short period of time to encourage participation. Both surveys were designed as anonymous surveys in Qualtrics in order to preserve student anonymity. The survey questions were designed to complement one another across both surveys, such that student responses could be matched with peer mentor responses. For example, the student survey asked students to rate the following statement on a Likert scale: "My mentor helped my team to understand TECHNICAL course content." In the peer mentor survey, peer mentors were asked to rate the corresponding statement on a Likert scale: "I was valuable to the teams I mentored by helping students understand TECHNICAL course content." In doing so, peer mentors reporting helping students understand technical material could be compared with student perceptions of technical skill development. As such, the two surveys were designed together in order to highlight similarities and differences in student and peer mentor perceptions.

The survey content focused on several different interactions between students and peer mentors. First, the surveys attempted to capture the effects of peer mentors on individual student development and on student team development. For example, the student survey asked students to rate the following statements on a Likert scale: "My mentor helped to develop my TECHNICAL skills" and "My mentor helped my team to understand TECHNICAL course 
content". In doing so, the survey attempted to assess both the effects that peer mentors had on individual student learning (i.e., attempting to capture students' perception of mentors' effect on learning) as well as the effects that peer mentors had on student team success (i.e., attempting to capture students' perception of mentors' effect on performance). Corresponding statements were assessed in the peer mentor survey to capture how helpful peer mentors perceived themselves to be, with regards to technical skill development, for both individual students and student teams. Likert-style survey questions are included in Table 1.

Second, the surveys asked students and peer mentors to choose a specific list of tasks that peer mentors performed for their students, as well as selecting the total amount of time that peer mentors spent with students every week. By asking both students and peer mentors, student perceptions of peer mentors and peer mentor perceptions of their own actions could be quantified and compared. Third, the surveys asked students to list the most significant impacts that their peer mentors had on them, and it asked peer mentors to list the most significant impacts that they believed they had on their students. As such, the surveys focused heavily on peer mentor effectiveness as perceived by students versus peer mentor effectiveness as perceived by peer mentors.

Analysis of survey responses. The data collected from the Likert scale portion of the survey showed that peer mentoring had an overall positive effect on both peer mentors and students. In order to determine overall student experiences, the Likert scale responses were converted to a numerical scale from 1 to 5, with a response of "Strongly Disagree" receiving a score of 1 and a response of "Strongly Agree" receiving a score of 5. Overall, students and peer mentors reported that the peer mentoring experience had a positive impact on both students and peer mentors.

Overall, communication was the most important factor in the responses. Students and peer mentors agreed that assisting in communication skill development made the largest impact on both students and peer mentors. This communication component included not only the formal technical communication aspects of the course such as presentations, reports, and speaking skills, but also professional skills such as working with a diverse group of engineering students, facilitating teamwork, and staying on task.

Benefits to mentors. Most peer mentors are recruited from students who recently completed the course. For many, mentoring a student team is their first college teaching experience as well as an early college leadership experience. As such, it is expected that peer mentors mainly gain communication and leadership skills as a result of peer mentoring. When asked why they wanted to become a peer mentor, one peer mentored responded, "I thought it would be a good teaching opportunity that I could use in exploring other teaching opportunities at this university." Based on the Likert scale portion of the survey, communication skill growth scored the highest compared to leadership skill growth, technical skill growth, and other skill growth, with an average score of 4.0 out of 5 and a mode of 4 (agree). The distribution of responses can be seen in Figure 1. In response to the survey question, "Were there any other skills that you developed while being a peer mentor?" one peer mentor wrote, "My communication and creative skills were developed when assisting the new students through the design and build portions of the course. I assisted with their problems without giving complete answers allowing them to think for themselves as well." 


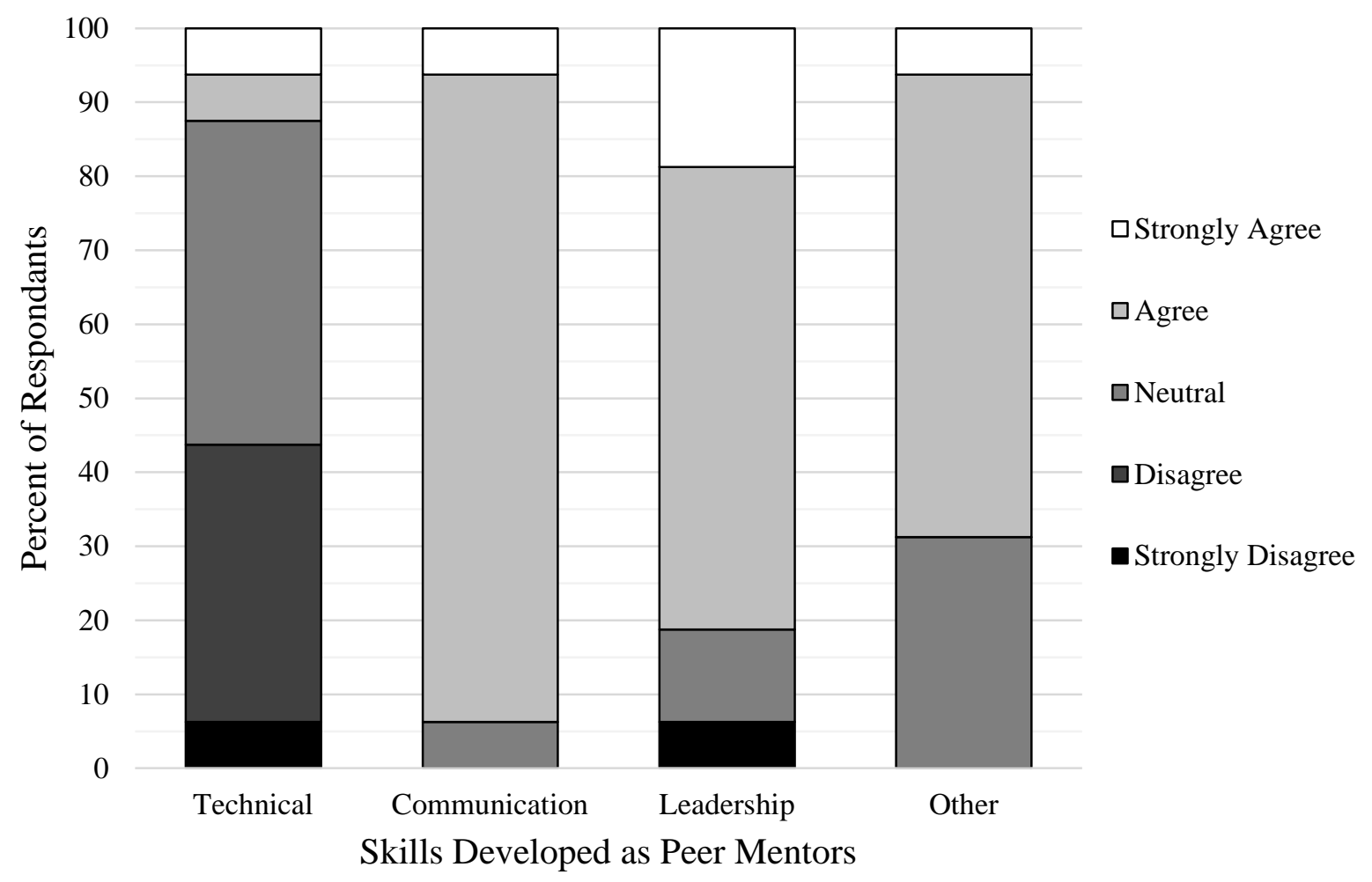

Figure 1. Distribution of responses to "Peer mentoring developed my XXX skills." This chart shows peer mentors' perceptions of skills they develop as peer mentors (Qs M1-M4 from Table 1)

The Likert scale data also suggested that peer mentors felt that this experience improved their leadership skills. Personal leadership growth scored an average of 3.9 out of 5, which was the second highest average score. One peer mentor wrote in the survey that, "It was a great way to develop leadership skills because my team really listened to what I had to say and would follow my advice, so I got experience talking them through the design/report process.".

However, the Likert scale data suggested that peer mentors did not feel that this experience improved their technical skills. Overall, personal technical skill growth scored below a neutral response with an average of 2.7 out of 5 and a mode of 3 (neutral). This is most likely attributed to the fact that peer mentors have already successfully completed the course, and as such, may not gain any additional technical skills from mentoring students. Finally, peer mentors also reported other skills growth with an average score of 3.8 out of 5 and with a mode of 4 (agree).

Based on the open-ended survey responses, peer mentors described their experience in working with student teams as beneficial in gaining multiple leadership skills. A skill that one peer mentor gained was "learning when to give input and when to let them figure it out on their own." The same peer mentor then went on to state, "There were some points where I found they were going down the wrong path and [I had to learn]... how to steer them away from problems without taking away the lesson they would have learned." As a result, most peer mentors found 
that peer mentoring was a beneficial experience in developing leadership and communication skills, as well as other skills not specified in this survey.

In comparison, students felt that the largest impact that peer mentors had on them was communication skill growth. Similar to the peer mentors' responses, students reported the highest agreement with peer mentors contributing to communication skill growth, with an average score of 3.6 out of 5 and with a mode of 4 (agree). The distribution of student responses can be seen in Figure 2. However, it is important to note that this may be due to the structure and content of the course. Some students initially struggle with the technical communication reporting aspect of the course and find the engineering communication to be unlike the communication skills they practice in high school. As such, peer mentors may find it natural to help students with communication skills as opposed to technical skills, causing communication skill growth to be cited as the most impactful skill growth for both students and peer mentors.

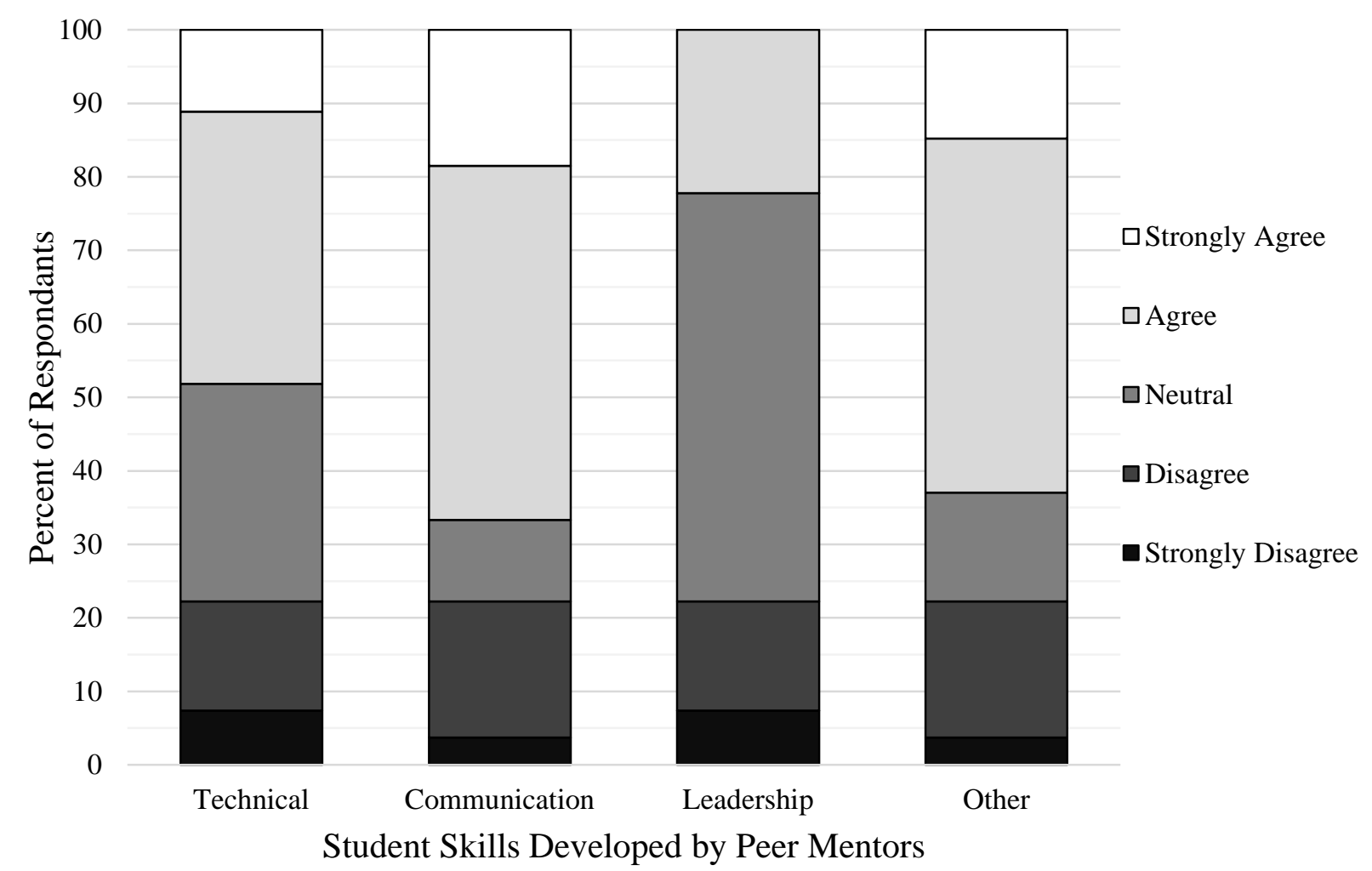

Figure 2. Distribution of responses to "My peer mentor developed my XXX skills." This chart shows students' perceptions of skills their peer mentor helped them develop. (Qs S1-S4 in Table 1)

Students attributed to their peer mentors high technical skill growth and low leadership skill growth. Technical skill growth scored an average of 3.3 out of 5 and with a mode of 4 (agree), while leadership skill growth scored an average of 2.9 out of 5 and with a mode of 3 (neutral). Once again, differences in technical skill growth can be attributed to the fact that peer mentors are recruited from students who have already successfully completed the course, while current 
students have not yet completed the course. Due to this important distinction, it is expected that peer mentors develop leadership skills from the mentoring experience, while students develop technical skills from participating in the course, and the surveys support this expectation. The full results of the Likert scale portion of the student and mentor surveys are listed in Table 1.

Table 1: Student and mentor perceptions of skill growth, attributable to the mentoring experience

\begin{tabular}{l} 
Question \\
\hline Student Responses
\end{tabular}

S1. My mentor helped to develop my TECHNICAL skills.

Average $\begin{gathered}\text { Standard } \\ \text { Deviation }\end{gathered}$ Mode

S2. My mentor helped to develop my COMMUNICATION skills.

S3. My mentor helped to develop my LEADERSHIP skills.

S4. My mentor helped to develop OTHER skills.

S5. My mentor helped my team to understand TECHNICAL course content.

S6. My mentor helped my team produce better COMMUNICATION work.

S7. My mentor facilitated better teamwork amongst my team.

S8. My mentor helped my team with non-course related problems.

(Such as other course advice, life on campus, etc.)

$\begin{array}{lll}3.30 & 1.10 & 4 \\ 3.59 & 1.12 & 4 \\ 2.93 & 0.83 & 3 \\ 3.52 & 1.09 & 4 \\ 3.85 & 1.10 & 4\end{array}$

Mentor Responses

M1. My experience as a mentor developed my TECHNICAL skills.

M2. My experience as a mentor developed my COMMUNICATION skills.

M3. My experience as a mentor developed my LEADERSHIP skills.

M4. My experience as a mentor developed OTHER skills.

3.89

$1.15 \quad 4$

3.93

$0.96 \quad 4$

3.78

1.12

4

M5. I was valuable to the teams I mentored by helping students understand TECHNICAL course content.

$\begin{array}{lll}2.69 & 0.95 & 3\end{array}$

$\begin{array}{lll}4.00 & 0.37 \quad 4\end{array}$

$3.88-0.96-4$

$\begin{array}{lll}3.75 & 0.58 \quad 4\end{array}$

M6. I was valuable to the teams I mentored by helping students produce better COMMUNICATION work.

M7. I was valuable to the teams I mentored by facilitating better teamwork.

$\begin{array}{lll}3.94 & 0.93 \quad 4\end{array}$

$\begin{array}{lll}4.19 & 0.54 \quad 4\end{array}$

$\begin{array}{lll}3.88 & 0.62 \quad 4\end{array}$

M8. I was valuable to the teams I mentored by helping students with non-course related problems. (Such as other course advice, life on campus, etc.)

Benefits to student teams. Overall, peer mentors were perceived to have had the largest impact on the team as a whole. Peer mentors and students responded positively to assisting in technical course content, facilitating team communication, facilitating teamwork, and helping with noncourse related problems. All four categories received high average scores, ranging from 3.8 to 4.2, from both peer mentors and students. The distributions of responses can be seen in Figure 3 . 


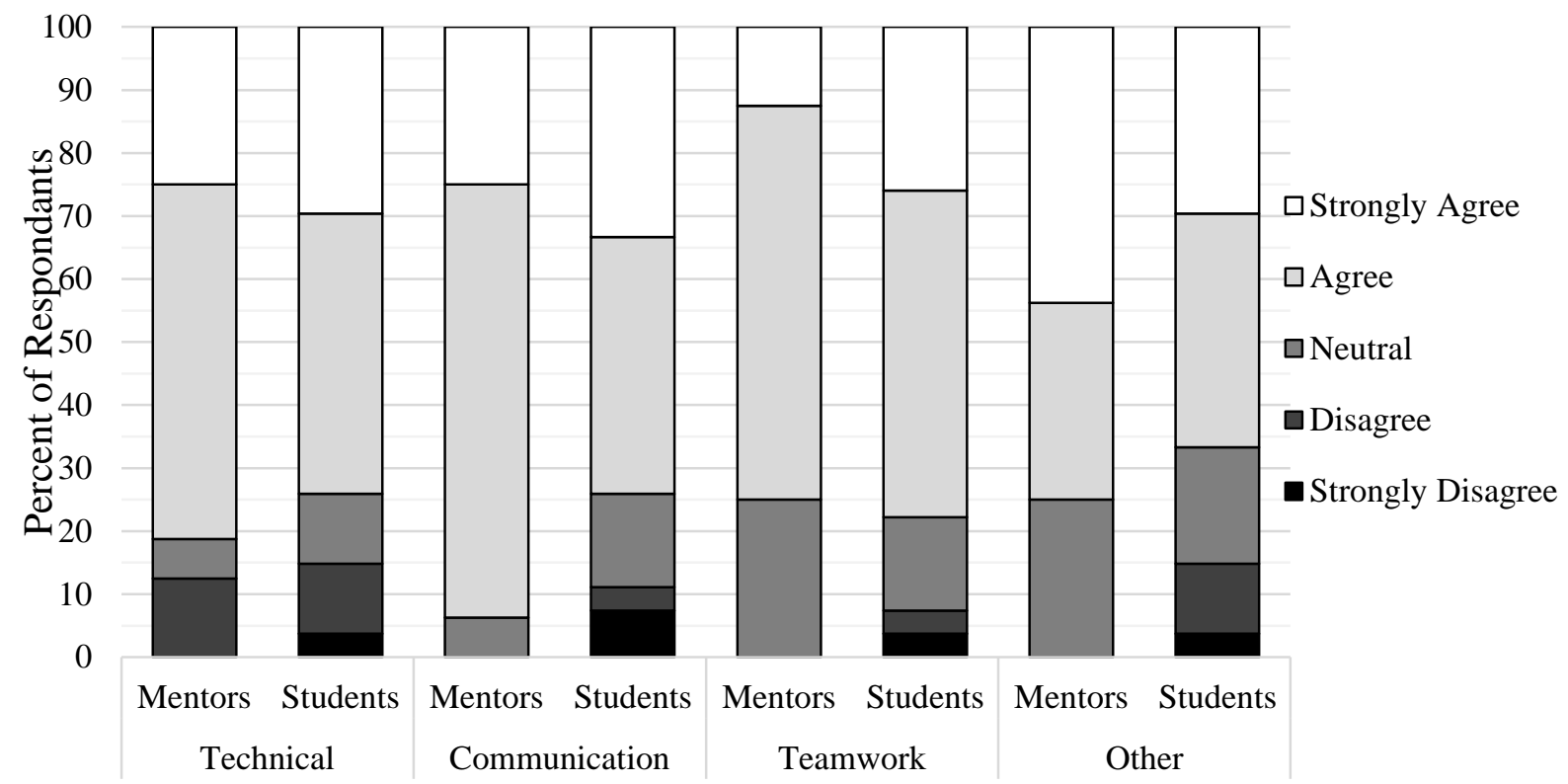

Figure 3. Mentor and student responses to effect of mentors on each of these learning outcomes (Qs S5-S8 and M5-M8 in Table 1)

Questions also asked about mentor behaviors and their effects on student teams. Peer mentors reported commonly assisting in the technical aspects of the projects by providing examples of previous project designs to spur ideas. All peer mentor respondents reported giving examples of previous project designs, and $93 \%$ of students reported receiving examples. While most students felt this was helpful, one student wrote in the survey that, "having the previous designs to work from is helpful, but at the same time I think it does take away from the design process. Once you see a design that you like and you know that it works really well, it's hard to change components of the design." It was suggested that only descriptions of previous designs should be provided instead of showing photos to help combat this effect.

Additionally, the simple presence of the peer mentors for the teams during both lab classes and team meetings outside of class time was helpful for students. Students report that having the peer mentors available for feedback on written and oral reports, rehearsing presentations, and keeping the team on task are all helpful. One student wrote that the largest impact their peer mentor made on the team was attending the team meetings. Another student mentioned their peer mentor "keeping the team directed towards our main goal, even when members of the team such as myself seemed inclined to pursue insignificant tangents to the main design."

However, one comment was made by a peer mentor who felt that it was less valuable for the peer mentors to remain in the labs during the construction phase of the projects. The mentor added, "There was a lot of sitting around because we couldn't get involved and they did not need input once all the pieces were made and just needed to be put together. Most important time to have the mentors was for brainstorming and designing, and at the end for reports and presentations." 
Most peer mentors (81\%) and students (85\%) reported that their peer mentors attended meetings outside of class time. Additionally, peer mentors (69\%) and students (70\%) reported rehearsing their presentations together. When peer mentors did not come to meetings outside of class, students reported that they felt "somewhat stranded and on our own" and believed it negatively impacted their performance. Table 2 shows the coding for the responses of what peer mentors did to help the teams, and Figure 4 shows the frequency of those responses.

Table 2. Ways in which peer mentors helped the team

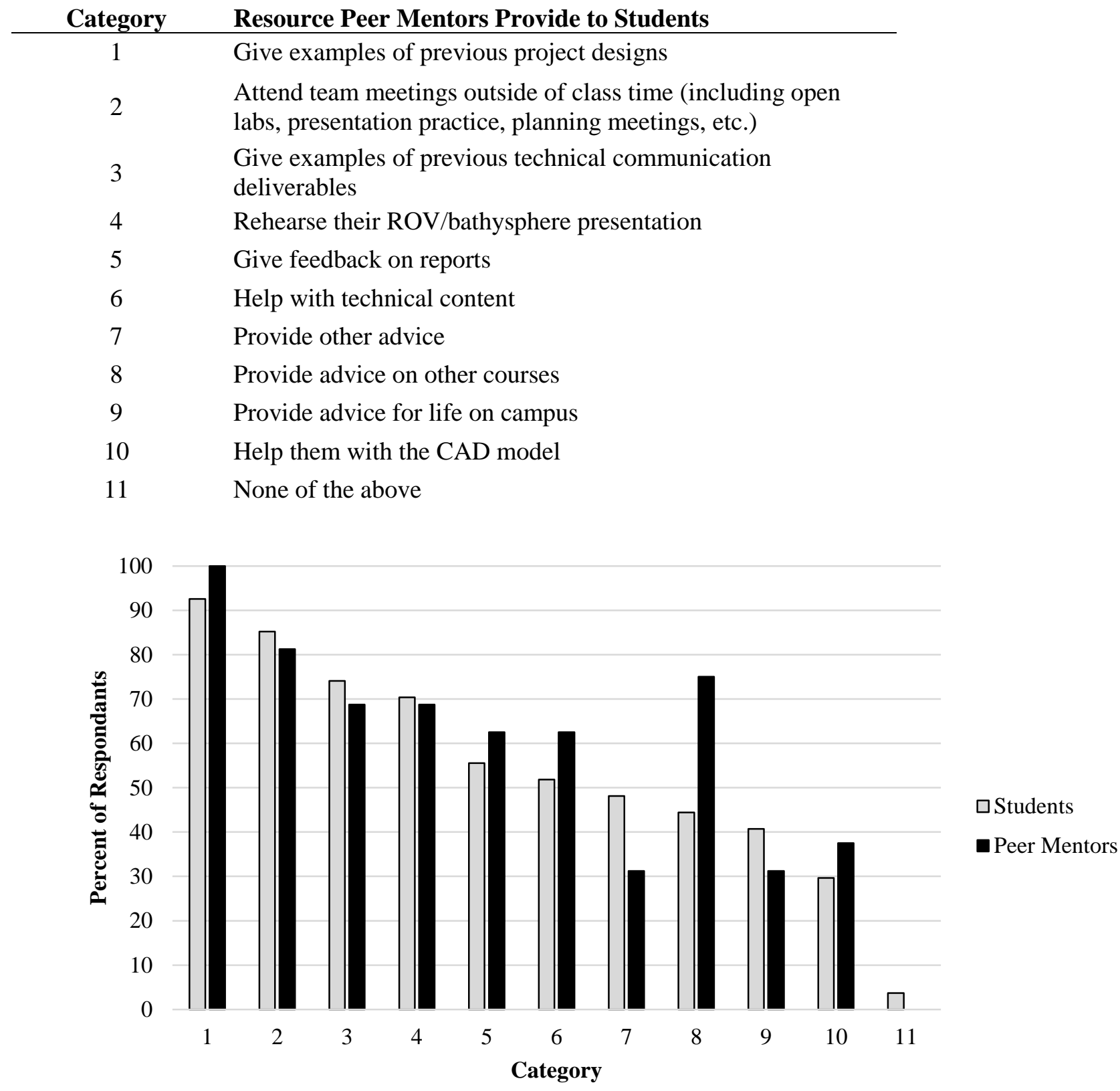

Figure 4. Frequency with which students and peer mentors report the types of assistance (from Table 2) 
As can be seen, there is generally agreement between mentors and students. Both mentors and students respond with high frequency that mentors help teams by providing examples of previous designs and reports, by attending open labs, and by rehearsing presentations with teams. There is more disagreement with tasks later on this list, and in particular, many more mentors than students report that mentors help by providing advice on other courses, likely because such conversations happen between a mentor and a single student (i.e., the whole team is aware when the mentor rehearses with the team, but only one student of the team is aware of the conversation in which the mentor encourages one student to take a particular upper division engineering course. The survey would then capture lots of students who aren't aware of this advice happening.)

Comments on current facilitation of mentoring experience. Students and peer mentors surveyed were also asked to evaluate the peer mentor selection and training process. Most responses indicated that the current system works well. One peer mentor commented, "I like the freedom approach with peer mentors. They get to participate in lab time and have students explain/justify [their] design and then make suggestions. I believe the system works well." Another student added, "Peer mentors are well equipped to be able to really make a difference in the attitude and performance of their teams."

Some peer mentors and students suggested holding an interview for peer mentors prior to their selection. There were some complaints of peer mentors not spending enough time with their groups. Both students and peer mentors alike suggested ensuring that peer mentors fully understood the expectations and time commitment of being a peer mentor, as well as making sure that they set aside the necessary time to invest in their student groups.

Some peer mentors also requested more training, and one student suggested that they review some of the basic concepts taught in the class. One consistent problem that occurs from semester to semester is peer mentors not reading new project specifications, resulting in advice on old formulations of the projects that are no longer relevant to the course.

\section{Instructor remarks on peer mentoring experience}

Facilitating the peer mentors adds an additional organizational layer to a course that already has many moving parts. However, the instructors feel that including peer mentors in the course has had beneficial effects, and that the additional work is worth it. Specifically, we would point to a few benefits of peer mentors as reasons to justify the extra work involved:

An extra layer of contact with student teams. Peer mentors are undergraduate students themselves, so students sometimes interact with them differently than they do faculty. Additionally, a mentor's focus is entirely supportive (the mentors do not evaluate the teams). Perhaps because of these characteristics, some students are more likely to bring concerns and questions to mentors than to the course instructors. Additionally, a mentor is responsible for one team and sees the team interact both inside and outside of class time; even our undergraduate instructional assistants, who are in lab time with the students (including evening open labs), do not have this amount of contact with each team, and often are spreading their attention over four or more teams. From mentors, we often hear early warnings about teams or individuals who are 
falling behind or misunderstanding course expectations. Sometimes, mentors are able to address the issues on their own; other times, they alert instructors, who address misconceptions, meet with teams to discuss team dynamics issues, and so on, as needed.

A beneficial experience for mentors, who develop leadership skills and reinforce class content. We believe that mentoring helps students develop some of the professional skills that will be important for them as engineers, and we are glad to give excellent students the opportunity to practice those skills.

A beneficial experience for students, who get small group instruction in the moment when it is needed. Though faculty strive to provide the needed course instruction during class time, students inevitably encounter topics outside of our initial plan that they must master: this is the nature of an open-ended design project. Mentors, who meet with teams as they work through the open-ended project, have the opportunity to help students learn new content, as well as to provide direct, differentiated, in-the-moment instruction on previously covered topics. Students report learning benefits from this additional support.

A pipeline for us to identify and retain excellent students. We like to retain excellent students as peer mentors, and excellent mentors as instructional assistants. Not only does this keep excellent students as part of the course, it preserves institutional memory.

Potential pitfalls. Our use of mentors has evolved over the semesters that we have been teaching the course, and we think anyone considering integrating mentors should be aware of potential pitfalls (and how we have worked to mediate them).

One major disadvantage of mentors, which is attested to in the survey reported here, is that mentors will share previous students' work, and students may not have the same "design from scratch" experience. In our experience, sadly, this was the case even without mentors: students upload their reports to shared work sites and portfolio sites, and videos of their designs to YouTube. New students have access to and find these examples, so students have access to previous students' work whether or not we include mentors in the equation. One way to mediate this issue is to change the project specifications or assessment (or the project, more radically) semester-to-semester, so that the same designs that are successful in one context may not be in another. It is also important to make sure that students and mentors know that changes have been made and to have a conversation with mentors and encourage them to focus on students' learning, rather than performance, goals. This year, we've provided a reading from a graduate student instructor training manual ${ }^{[9]}$ to enable a discussion about our goals for mentors, with the goal that mentors can help students be more intentional about the design, rather than unreflectively adopting strategies they see in previous work, whether that work is mentor provided or found in other ways.

A second disadvantage of mentors is that they may give students erroneous information. In our experience, this has happened primarily when mentors do not carefully read project specifications that have changed, and they give teams information that was true in a previous semester but is no longer the case. We have worked to combat this issue by reminding mentors at the beginning of their mentoring that the project may have changed, and by highlighting changes as they are made. 
Future plans. Based on reports from mentors that one of the more valuable aspects of mentoring was developing pedagogical and leadership skills, we plan to focus on this skill development more intentionally. Specifically, we will add two additional short readings on leadership of diverse teams, and we will ask mentors to write short reflections (a few paragraphs) at three or four time points during the semester. We believe this scaffolded reflection will enhance mentors' learning and retention of this critical information, as shown in other studies of double loop learning and scaffolded reflection ${ }^{[10,11]}$.

\section{Suggested Best Practices for Working with Peer Mentors}

Over five years of teaching this course, we have found that certain practices for mentor recruitment and facilitation have improved the project experience for students, mentors, and instructors. For example, we:

- Recruit excellent former students of the course to be mentors, and we recruit excellent mentors to be course Instructional Aides (who run the labs and the competitions, and who hold office hours and perform other instructional duties). This pipeline helps us identify strong students for important course roles and also preserve institutional memory.

- Assign mentors at the laboratory level, so that student teams are guaranteed to have weekly face-to-face time with the assigned mentor.

- Use Google Forms to gather updates from mentors on team progress and team functioning, which we review in weekly instructor meetings. Based on the feedback, we might choose to intervene with teams, provide supplemental instruction on specific topics, open the laboratory for additional building hours, etc. Before we used the Google Forms, only some mentors initiated communication with us when their teams were experiencing initial problems. Others waited until the problems had become severe: the weekly required check-ins have allowed us to know about issues sooner.

- Provide careful instruction to mentors regarding how to interact with groups in ways that recognize individual contributions and that support learning rather than performance.

\section{Limitations of This Work}

This paper reports on an assessment of peer mentoring as it is conducted in a first year designbuild-test-communicate class, and it finds both promising benefits and potential weaknesses of the current pedagogical implementation of mentors. Importantly, the assessment rests on student and mentor self-report information, rather than actual performance measures. Further research should consider how performance measures can compare teams with mentors to teams without, or teams with mentors who perform certain functions to teams whose mentors do not.

Additionally, there is no comparison group of students who did not receive mentoring to compare the mentored students to. Other sections of the course at the university have different project foci (e.g., build underwater vehicles vs. build a wind turbine vs. design but-not-build a biomedical device), different levels of open-endedness of the project, different team sizes, different lengths of the project, etc. Our section, which has evolved somewhat in each of these ways but has stayed relatively consistent, has used peer mentors in all of its iterations. 
Finally, the response rates were fairly low (24\% of students and $44 \%$ of mentors completed the surveys). We do not know which students and mentors responded, so we can not compare responders and non-responders to see if they are different in various ways.

[1] Good, J. M., Halpin, G., \& Halpin, G. (2001). A promising prospect for minority retention: Students becoming peer mentors. Journal of Negro Education, 69(4), 375-383.

[2] Brainard, S. G., \& Carlin, L. (1998). A six-year longitudinal study of undergraduate women in engineering and science. Journal of Engineering Education, BLAH, 369-375.

[3] Crisp, G., \& Cruz, I. (2009). Mentoring college students: A critical review of the literature between 1990 and 2007. Research in Higher Education, 50(6), 525-545. doi:10.1007/s11162009-9130-2

[4] Hug, S., Thiry, H., \& Tedford, P. (2011). Learning to love computer science: Peer leaders gain teaching skill, communicative ability and content knowledge in the CS classroom. In Proceedings of the 42nd ACM Technical Symposium on Computer Science Education, 201-206. DOI: $10.1145 / 1953163.1953225$

[5] Stout, L. M., \& McDaniel, A. J. (2006). Benefits to supplemental instruction leaders. New Directions for Teaching and Learning, 106, 55-62. DOI: 10.1002/t1.233

[6] Oakley, B. A., \& Finelli, C. J. (2014). A practical approach to understanding-and applying! - the scholarship of application. IEEE Transactions on Education, 57(2), 69-74. DOI: 10.1109/TE.2014.2313036

[7] Johnson, E. C., Robbins, B. A., \& Loui, M. C. (2015). What do students experience as peer leaders of learning teams? Advances in Engineering Education, 4(1), 1-22.

[8] Meadows, L. A., Fowler, R., \& Hildinger, E. S. (2012, June), Empowering Students with Choice in the First Year. Paper presented at 2012 ASEE Annual Conference \& Exposition, San Antonio, Texas. https://peer.asee.org/21282

[9] Hiemstra, R. (2001). Uses and benefits of journal writing. New Directions for Adult and Continuing Education, 90, 19-26. DOI: 10.1002/ace.17

[10] Greenwood, J. (1998). The role of reflection in single and double loop learning. Journal of Advanced Nursing, 27, 1048-1053. 